\title{
Bacterial community change through drinking water treatment processes
}

\author{
X. Liao $\cdot$ C. Chen $\cdot$ Z. Wang $\cdot$ C.-H. Chang $\cdot$ \\ X. Zhang $\cdot$ S. Xie
}

Received: 28 August 2012/Revised: 30 September 2013/ Accepted: 5 March 2014/Published online: 18 March 2014

(C) Islamic Azad University (IAU) 2014

\begin{abstract}
The microbiological quality of drinking water has aroused increasing attention due to potential public health risks. Knowledge of the bacterial ecology in the effluents of drinking water treatment units will be of practical importance. However, the bacterial community in the effluents of drinking water filters remains poorly understood. The changes of the density of viable heterotrophic bacteria and bacterial populations through a pilot-scale drinking water treatment process were investigated using heterotrophic plate counts and clone library analysis, respectively. The pilot-scale treatment process was composed of preozonation, rapid mixing, flocculation, sedimentation, sand filtration postozonation, and biological activated carbon (BAC) filtration. The results indicated that heterotrophic plate counts decreased dramatically through the drinking water treatment processes. Clone library analysis indicated the significant change of bacterial community structure through the water treatment processes. Betaproteobacteria was dominant in raw water, the sand filter effluent and the BAC filter effluent. This work could provide some new insights on drinking water microbial ecology.
\end{abstract}

Keywords Biological activated carbon - Drinking water treatment system - Sand filter - Microbial community

Xiaobin Liao and Chao Chen have contributed equally to this study.

X. Liao $\cdot$ C. Chen $\cdot$ X. Zhang

School of Environment, Tsinghua University, Beijing 100084, China

Z. Wang $\cdot$ C.-H. Chang $\cdot$ S. Xie $(\bowtie)$

College of Environmental Sciences and Engineering, The Key

Laboratory of Water and Sediment Sciences (Ministry of

Education), Peking University, Beijing 100871, China

e-mail: xiesg@pku.edu.cn

\section{Introduction}

The microbiological quality of drinking water has aroused increasing attention due to potential public health risks. The conventional treatment process, composed of coagulation-flocculation, sedimentation, rapid sand filtration, and disinfection, is still widely used by drinking water producers to remove turbidity and pathogens. The conventional treatment process is not efficient in removal of biodegradable dissolved organic carbon (BDOC) that is mainly responsible for the microbial regrowth in drinking water distribution systems (DWDS). Biological activated carbon (BAC) filtration can perform well in reduction of organic pollutants after the attachment of the indigenous microbiota attached to the porous surface of granular activated carbon (GAC). BAC filters are important for their capacity to biodegrade undesirable compounds. In addition, the combination of ozonation with BAC filtration has proven to be an efficient method in reduction in BDOC (Yapsakli and Cecen 2010). However, biomass developed in biofilters might be a source of bacterial contamination in DWDS (Niemi et al. 2009; Liao et al. 2012). Therefore, concerns regarding the microorganisms in the effluents of filters have been raised (Norton and LeChevallier 2000; Poitelon et al. 2010). Pathogenic or opportunistic microorganisms from may enter DWDS as a result of improper management (Villarreal et al. 2010).

The heterotrophic plate count (HPC), as a culturedependent method, has been widely used to estimate the density of viable heterotrophic bacteria in drinking water and is still considered very useful for assessing the general microbial water quality (Sartory et al. 2008). However, only a small fraction of the viable bacterial cells present in drinking water could be identified using the traditional culture-dependent methods (Eichler et al. 2006; Sartory et al. 
2008). Molecular methods have been widely used to characterize the microbial community dynamics in drinking waters in DWDS (Berry et al. 2006; Revetta et al. 2010), and drinking water biofilters (Kasuga et al. 2007; Feng et al. 2012; Liao et al. 2012). Since the presence of certain bacteria may lead to water quality problems in the downstream DWDS, knowledge of the bacterial ecology in the effluents of drinking water treatment units will be of practical importance. Unfortunately, only very few works have investigated the microbial communities in the effluents of drinking water treatment units (Eichler et al. 2006; Poitelon et al. 2010). Therefore, the bacterial community in the effluents of drinking water filters remains poorly understood.

It is generally accepted that chlorination can result in a dramatic shift in the composition of the bacterial community (Norton and LeChevallier 2000; Eichler et al. 2006; Kormas et al. 2010; Poitelon et al. 2010), yet little information is available on the bacterial community change through other drinking water treatment units. Pinto et al. (2012) found that filtration by dual media rapid sand filters in a drinking water plant played a primary role in shaping the bacterial community in DWDS. The main aim of the current study was to assess bacterial community change through drinking water treatment processes. The bacterial populations in raw water, the sand filter effluent, and the BAC filter effluent were compared. For each water sample, genomic DNA was extracted followed by construction of 16S rRNA gene clone library. Water samples were collected from a combined pilot-scale drinking water treatment system treating lake water operated in Jiangsu Province (China) in June 2012. Molecular analysis was carried out between June and August in 2012 at College of Environmental Sciences and Engineering, Peking University, China.

\section{Materials and methods}

Water samples

A pilot-scale drinking treatment system was constructed to treat surface water retrieved from a small lake, in Jiangsu Province. The whole treatment process was composed of preozonation, rapid mixing, flocculation, sedimentation, sand filtration postozonation, and BAC filtration (Fig. 1). In this study, the BAC filter was operated in downflow mode. Before this study, the pilot-scale drinking treatment system had been operated for approximately ten months allowing for biofilm maturation. The operating parameters of the pilot-scale system were shown in Table 1 .

Water samples in three replicates were collected from raw water, the sand filter effluent, and the BAC filter effluent, referred to as Samples A, B, and C, respectively. The three samples were collected in the order of Sample C, B and A. The replicate water samples at each location were collected at an interval of a week. HPCs were measured using R2A medium according to the standard methods (APHA, Awwa, WEF 1995). Temperature was measured using a JPBJ-608 DO meter (Shanghai, China), while $\mathrm{pH}$ was measured using a PHSJ3F $\mathrm{pH}$ meter (Shanghai, China). Turbidity was measured according to the standard methods described by China Environmental Protection Agency (2002). Samples for dissolved organic carbon (DOC) concentration were filtered through 0.45$\mu$ m-pore-size Whatman GF/F filters and analyzed with a SHIMADZU Total Organic Carbon Analyzer (Shimadzu, Japan).

\section{Clone library analysis}

The triplicate water samples $(1 \mathrm{~L})$ from each sampling location were pooled. The pooled water samples were filtered through $0.22-\mu \mathrm{m}$-pore-size membranes (diameter $50 \mathrm{~mm}$; Millipore). The membrane filter was cut into quarters with a sterile scalpel, and each quarter was stored at $-20{ }^{\circ} \mathrm{C}$ for further molecular analysis (Huang et al. 2011). DNA for water sample was extracted using the E.Z.N.A. ${ }^{\circledR}$ Water DNA kit (Omega, USA) according to the manufacturer's protocol. 16S rRNA genes were amplified using bacterial primers 27F (5'-GAGTTTGATCMTGGC TCAG- $3^{\prime}$ ) and 1492R (5'-GGTTACCTTGTTACGACTT$3^{\prime}$ ) according to the literatures (Zhang et al. 2012; Wang et al. 2012). The PCR products were cloned into pMD19-T vector (Takara Corp, Japan) with ampicillin selection and blue/white screening. The clones containing correct size
Fig. 1 Schematic of the pilotscale drinking treatment system. Sample A, B, and C represent raw water, the sand filter effluent, and the biological activated carbon (BAC) filter effluent, respectively

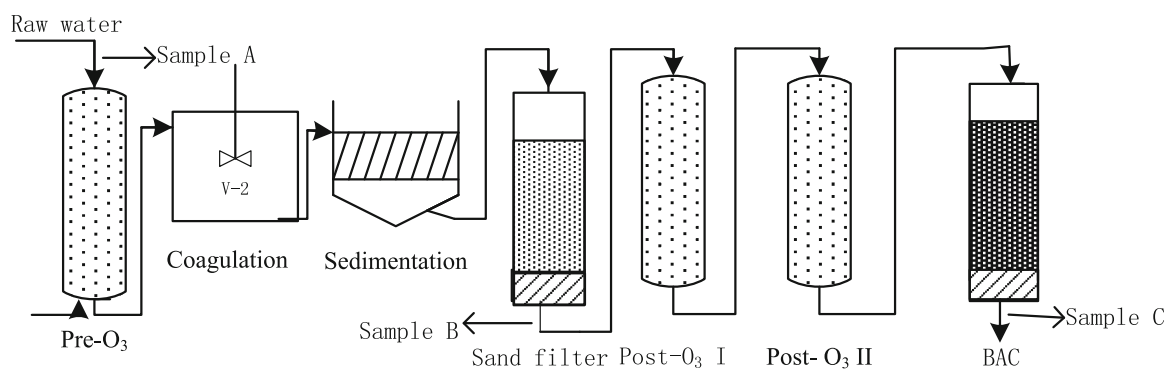


Table 1 Operating parameters of the pilot-scale drinking treatment system

\begin{tabular}{|c|c|c|}
\hline Process & Parameters & Designed or nominal values \\
\hline \multirow[t]{2}{*}{ Pre- $-\mathrm{O}_{3}$} & Contact time & $7.5 \mathrm{~min}$ \\
\hline & Ozone dose & $0.5 \mathrm{mg} \mathrm{L}^{-1}$ \\
\hline \multirow[t]{3}{*}{ Flocculation } & Paddle type & Three stages \\
\hline & $\begin{array}{l}\text { Retention } \\
\text { time }\end{array}$ & $18.66 \mathrm{~min}$ \\
\hline & $\begin{array}{l}\text { Coagulant } \\
\text { dose }\end{array}$ & $\begin{array}{l}50 \mathrm{mg} \mathrm{L}^{-1} \text { (as } 10 \% \text { liquid } \\
\text { aluminum) }\end{array}$ \\
\hline \multirow[t]{2}{*}{ Sedimentation } & $\begin{array}{l}\text { Inclined tube } \\
\text { type }\end{array}$ & $7.97 \mathrm{~min}$ \\
\hline & $\begin{array}{l}\text { Retention } \\
\text { time }\end{array}$ & \\
\hline \multirow[t]{3}{*}{ Sand filter } & Bed depth & $1,150 \mathrm{~mm}$ \\
\hline & Grain size & $0.8 \mathrm{~mm}$ \\
\hline & $\begin{array}{l}\text { Filtration } \\
\text { velocity }\end{array}$ & $8 \mathrm{~m} \mathrm{~h}^{-1}$ \\
\hline \multirow[t]{2}{*}{ Post- $\mathrm{O}_{3} \mathrm{I}$} & Contact time & $7.5 \mathrm{~min}$ \\
\hline & Ozone dose & $0.5 \mathrm{mg} \mathrm{L}^{-1}$ \\
\hline \multirow[t]{2}{*}{ Post- $\mathrm{O}_{3} \mathrm{II}$} & Contact time & $7.5 \mathrm{~min}$ \\
\hline & Ozone dose & $0.5 \mathrm{mg} \mathrm{L}^{-1}$ \\
\hline \multirow{3}{*}{$\begin{array}{l}\text { BAC filtration } \\
\text { columns }\end{array}$} & Bed depth & $1,000 \mathrm{~mm}$ \\
\hline & $\begin{array}{l}\text { Filtration } \\
\text { velocity }\end{array}$ & $8 \mathrm{~m} \mathrm{~h}^{-1}$ \\
\hline & Size & D) $400 \mathrm{~mm} \times 2,210 \mathrm{~mm}$ \\
\hline
\end{tabular}

Table 2 Water quality parameters at the time of sampling

\begin{tabular}{lccc}
\hline Parameter & Sample A & Sample B & Sample C \\
\hline Temperature $\left({ }^{\circ} \mathrm{C}\right)$ & $12.2 \pm 0.3$ & $12.2 \pm 0.3$ & $12.2 \pm 0.3$ \\
$\mathrm{pH}$ & $7.78 \pm 0.01$ & $7.35 \pm 0.02$ & $7.31 \pm 0.01$ \\
Turbidity (NTU) & $1.05 \pm 0.02$ & $0.57 \pm 0.03$ & $0.21 \pm 0.02$ \\
DOC $\left(\mathrm{mg} \mathrm{L}^{-1}\right)$ & $4.25 \pm 0.1$ & $3.35 \pm 0.07$ & $2.35 \pm 0.05$ \\
HPCs $\left(\mathrm{CFU} \mathrm{mL}{ }^{-1}\right)$ & $380 \pm 20$ & $43 \pm 7$ & $10 \pm 2$ \\
\hline
\end{tabular}

Sample A, B, and C represent raw water, the sand filter effluent, and the BAC filter effluent, respectively

were sequenced. Chimera-free sequences with $\leq 3 \%$ difference were clustered into operational taxonomic units (OTUs) using DOTUR program as well as the OTU-based richness and diversity indices were calculated (Schloss and Handelsman 2005). The Ribosomal Database Project analysis tool 'classifier' (http://rdp.cme.msu.edu/classifier/ classifier.jsp) was utilized to classify the taxonomic identities of the obtained bacterial sequences (Wang et al. 2007). Phylogenetic trees were constructed using MEGA software version 4.0 (Tamura et al. 2007). The sequences obtained in this study were submitted to GenBank under accession numbers JX464674-JX464708, and JX472014JX472030 for Sample A, JX464709-JX464763 for sample B, and JX464764-JX464818 for Sample C, respectively.
Table 3 Operational taxonomic units (OTUs)-based richness and Shannon index (calculated at 0.03 difference level) of three clone libraries

\begin{tabular}{lllll}
\hline Library & $\begin{array}{l}\text { Number of } \\
\text { clones }\end{array}$ & $\begin{array}{l}\text { Number of } \\
\text { OTUs }\end{array}$ & Chao1 & $\begin{array}{l}\text { Shannon } \\
\text { index }\end{array}$ \\
\hline $\begin{array}{c}\text { Sample } \\
\text { A }\end{array}$ & 52 & 33 & 79 & 3.26 \\
$\begin{array}{c}\text { Sample } \\
\text { B }\end{array}$ & 55 & 25 & 46 & 2.86 \\
$\begin{array}{c}\text { Sample } \\
\text { C }\end{array}$ & 55 & 18 & 36 & 2.13 \\
\hline
\end{tabular}

Sample A, B, and C represent raw water, the sand filter effluent, and the BAC filter effluent respectively. These data represent the composite results from three samples

\section{Results and discussion}

Water quality

Table 2 showed the bacteriological and physicochemical analyses of raw water, the sand filter effluent, and the BAC filter effluent. The results indicated that turbidity, DOC, and HPCs decreased dramatically through the treatment processes. The HPCs in the sand filter effluent and the BAC filter effluent were relatively low, compared with the worldwide recommend drinking water HPC limits (100-500 $\mathrm{cfu} \mathrm{mL}^{-1}$ ) (Pavlov et al. 2004).

\section{Bacterial community structures}

In this study, the triplicate water samples from each sampling location were pooled.

16S rRNA gene clone library was constructed for each pooled sample, and 162 total chimera-free sequences were obtained in this study. Sequences with $\geq 97 \%$ similarity were grouped into OTUs, and the richness and diversity indices were calculated (Table 3). The results indicated 33, 25, and 18 distinct OTUs in Sample A, B, and C, respectively. Richness (Chao1) and diversity indices (Shannon index) decreased dramatically through the treatment processes. Some types of bacterial species could be removed during the treatment process, so bacterial diversity can be expected to decrease. However, rarefaction curve for each bacterial library failed to level off completely, suggesting that further sequencing would have resulted in more OTUs (Fig. 2).

Alphaproteobacteria, Betaproteobacteria, Actinobacteria, and Bacteroidetes were shared among all the three samples (Fig. 3). Alphaproteobacteria was abundant in Sample A (15.4 \%) and Sample C (16.4\%), but significantly decreased in Sample B (3.6 \%). Betaproteobacteria was also abundant in Sample A (17.3\%) and obtained a significant increase in Sample B (32.7\%) and Sample C 


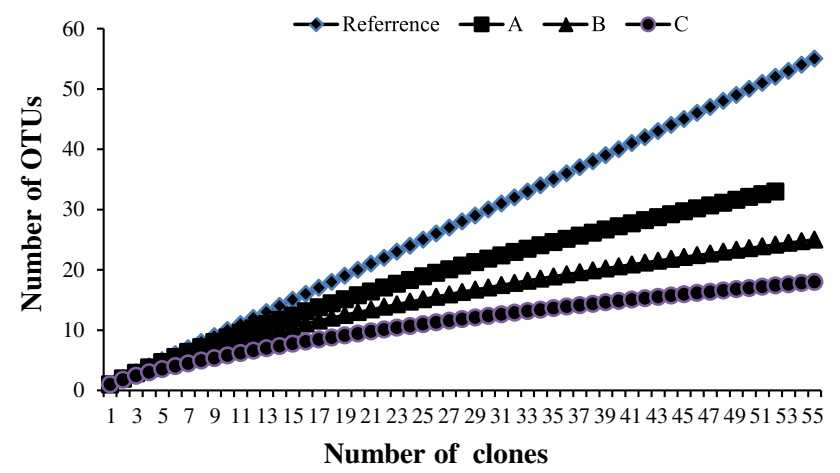

Fig. 2 Rarefaction curves indicating bacterial 16S rRNA gene richness within the three clone libraries. Sample A, B, and C represent raw water, the sand filter effluent, and the BAC filter effluent, respectively. The reference line represents $1: 1$, indicating infinite diversity

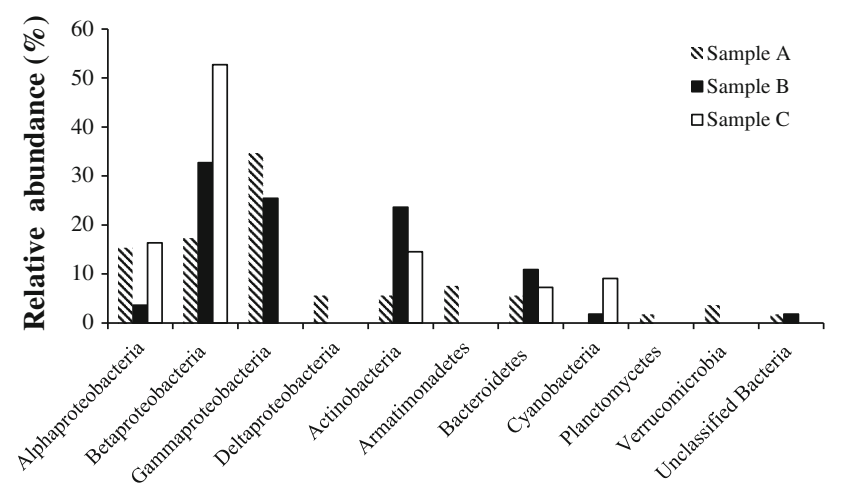

Fig. 3 Changes of the bacterial groups through the treatment processes. Sample A, B, and C represent raw water, the sand filter effluent, and the BAC filter effluent, respectively
(52.7\%). Gammaproteobacteria was the largest bacterial group in Sample A (34.6\%), but significantly decreased in Sample B (25.5\%) and was not detected in Sample C. Actinobacteria was a minor component in Sample A (5.8\%), but became one of the major groups in the other samples (23.6 or $14.5 \%$ ). Therefore, the major bacterial groups and their relative abundance changed greatly through the treatment processes.

Bacterial community change through the drinking water treatment units has still been poorly characterized. Eichler et al. (2006) found that no major changes of bacterial community structures occurred after flocculation and sand filtration. In contrast, Pinto et al. (2012) found that filtration by dual media rapid sand filters could shape the bacterial community in waters. Based on the significant difference between bacterial communities in raw water and on BAC, Soonglerdsongpha et al. (2011) suggested that bacterial community structure changed along the BAC filtration process. Previous studies showed the shift of bacterial community structure inside BAC systems (Liao et al. 2012, 2013) and granular activated carbon-sand dual media filter (Feng et al. 2013a). However, an earlier work using culture-dependent method indicated that BAC filtration did not change the nature of the bacterial populations associated with drinking water (Burlingame et al. 1986). Preozonation can usually effectively remove bacteria in water, while Burlingame et al. (1986) showed that preozonation of the water before BAC filtration had no noticeable effect on the bacterial genera found as compared with BAC filtration unit having no preozonation. Further efforts will be necessary in order to elucidate the bacterial

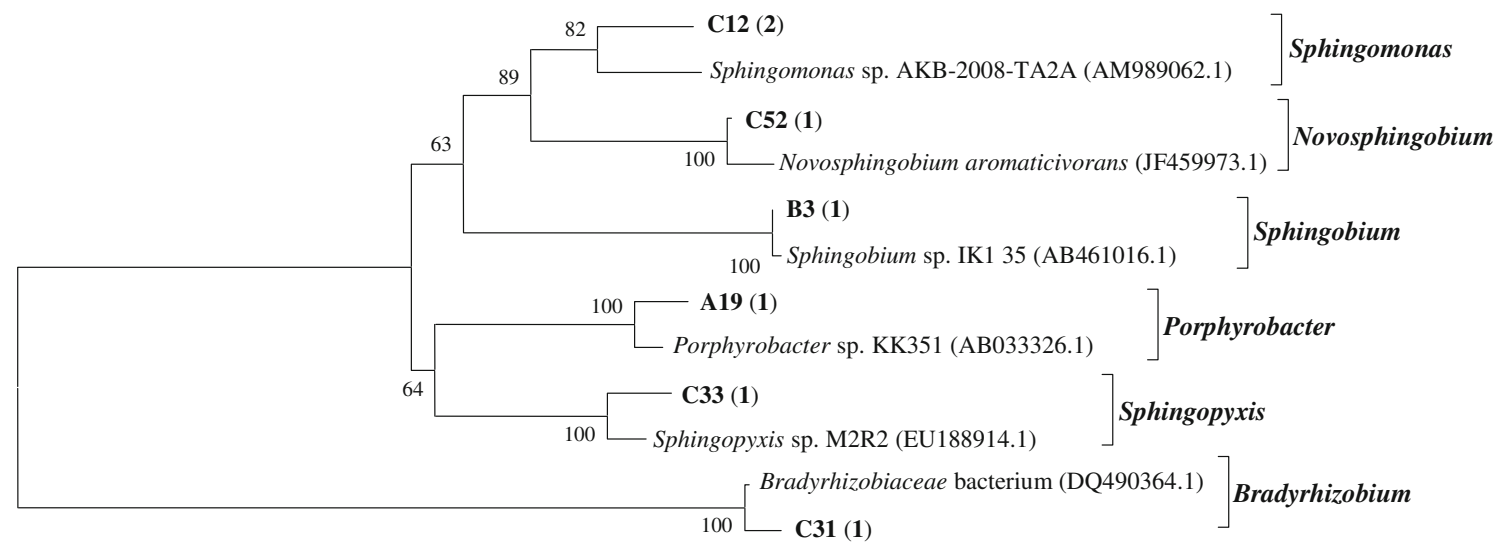

$\longmapsto$

Fig. 4 Phylogenetic tree of representative 16S rRNA gene sequences assigned with putative genus within Alphaproteobacteria and reference sequences from GenBank. The obtained sequences beginning with 'A,' 'B,' and 'C' were referred to sequences recovered from Sample A, Sample B, and Sample C, respectively. Sample A, B, and $\mathrm{C}$ represent raw water, the sand filter effluent, and the BAC filter effluent, respectively. The bold number in parentheses represents the numbers of the sequences in the same genus. Numbers at the nodes indicate the levels of bootstrap support based on neighbor-joining analysis of 1,000 resampled datasets. Bootstrap values $<50$ are not shown. The bar represents $0.5 \%$ sequence divergence 
community change through the drinking water treatment units. In this study, the preozonation followed by flocculation and sand filtration greatly altered the bacterial community in water. BAC filtration could further play an important role in shaping the aquatic bacterial community.

The phylogenetic composition of freshwater bacterial community has been well documented. Freshwater bacteria commonly belong to Cyanobacteria, Bacteroidetes, Alphaproteobacteria, Betaproteobacteria, and Gammaproteobacteria, Actinobacteria and Verrucomicrobia (Zwart et al. 2002; Huang et al. 2011). The structure of the bacterioplankton communities is dependent on a wide variety of factors. In this study, most of the bacterial sequences in each sample were affiliated with these groups. Moreover, substantial knowledge on microbial ecology and bacteria in real and model DWDs has been obtained (Berry et al. 2006; Lu et al. 2013). Alphaproteobacteria, Betaproteobacteria, and Gammaproteobacteria have usually been found to be the major groups in chlorinated drinking water (Domingo et al. 2003; Williams et al. 2004; Eichler et al. 2006). However, Cyanobacteria were found to be one of major groups in chlorinated drinking water in a real

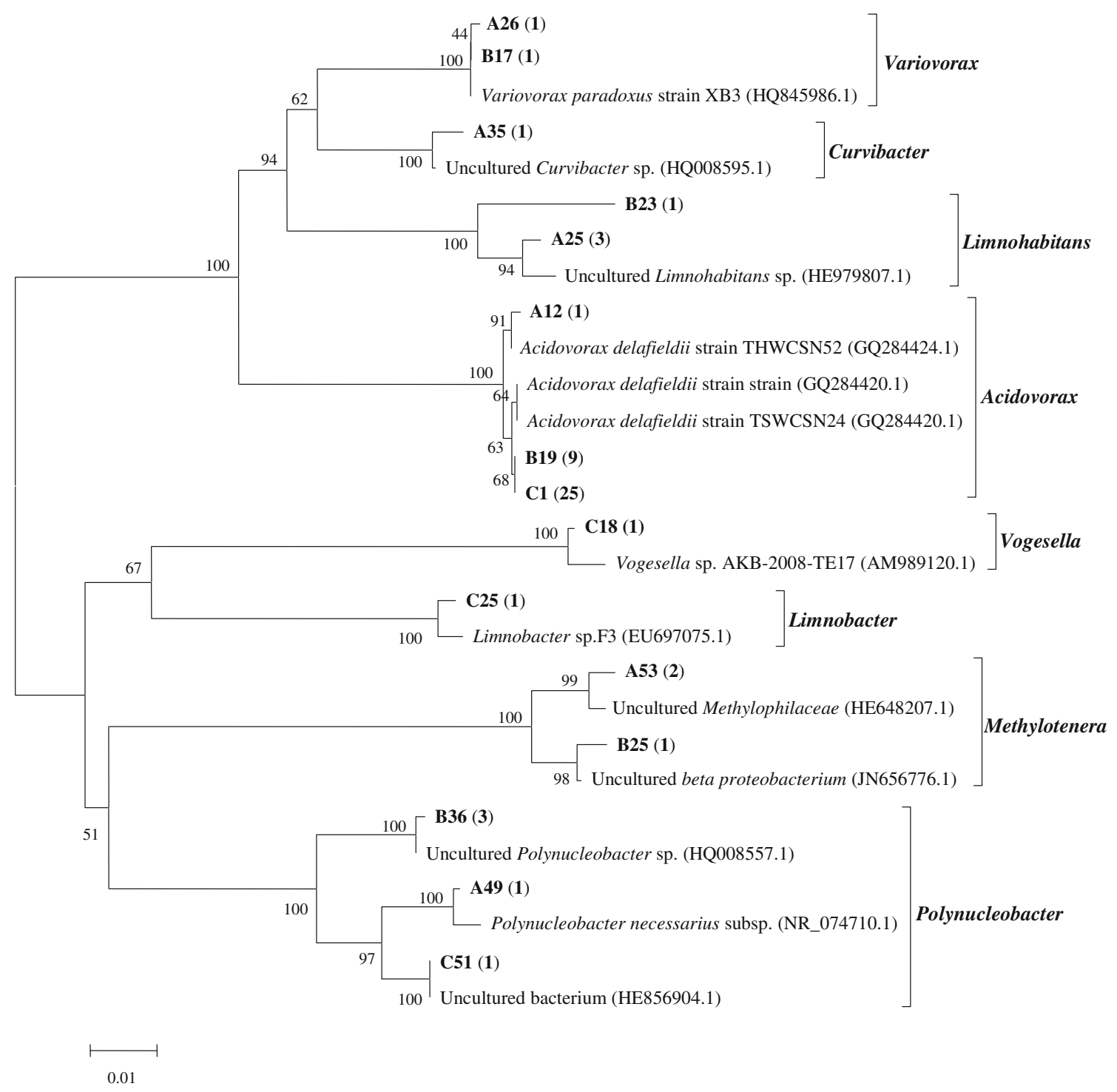

Fig. 5 Phylogenetic tree of representative 16S rRNA gene sequences assigned with putative genus within Betaproteobacteria and reference sequences from GenBank. The obtained sequences beginning with 'A,' 'B,' and 'C' were referred to sequences recovered from Sample A, Sample B, and Sample C, respectively. Sample A, B, and C represent raw water, the sand filter effluent, and the BAC filter effluent, respectively. The bold number in parentheses represents the numbers of the sequences in the same genus. Numbers at the nodes indicate the levels of bootstrap support based on neighbor-joining analysis of 1,000 resampled datasets. Bootstrap values $<50$ are not shown. The bar represents $1 \%$ sequence divergence 
DWDs (Lu et al. 2013). Moreover, the composition of the bacterial community in chlorinated (or chloraminated) water might be much different from that in non-chlorinated (or non-chloraminated) water (Norton and LeChevallier 2000; Berry et al. 2006; Eichler et al. 2006; Kormas et al. 2010; Poitelon et al. 2010). Unfortunately, very few research works have provided the phylogenetic description of bacterial community in the sand filter effluent and the BAC filter effluent. Using culture-dependent technique, Norton and LeChevallier (2000) found that Pseudomonas (affiliated with Gammaproteobacteria) and Sphingomonas (affiliated with Alphaproteobacteria) were the predominant isolates in the BAC filter effluent. A recent study using clone library analysis indicated that Alphaproteobacteria and Betaproteobacteria were predominant in the BAC filter effluent (Poitelon et al. 2010). In this study, Alphaproteobacteria, Betaproteobacteria, and Actinobacteria were found to be major bacterial groups in the BAC filter effluent.

Feng et al. (2013b) found that Nitrospirae and Alphaproteobacteria were the dominant bacterial groups in a full-scale drinking water biosand filter. Nitrospirae, Alphaproteobacteria, Acidobacteria, and Betaproteobacteria were the dominant groups in a granular activated carbonsand dual media filter for drinking water treatment (Feng et al. 2013a). Li et al. (2010) found that Betaproteobacteria was the most abundant bacterial group both in bench-scale and pilot-scale BAC reactors. Alphaproteobacteria, Gammaproteobacteria, and Acidobacteria were the major bacterial groups in a pilot-scale up-flow BAC filtration system (Liao et al. 2012).

A recent study indicated Alphaproteobacteria and Acidobacteria were the largest two bacterial groups inside a downflow BAC filtration system (Liao et al. 2013). Moreover, in the last GAC sampling point before leaving the BAC system, Betaproteobacteria and Actinobacteria were not detected or detected in very low abundance (Liao et al. 2013). The BAC filtration system was the same as that used in this study. However, in the BAC filter effluent, Acidobacteria was not detected, while Betaproteobacteria and Actinobacteria were the dominant groups. Therefore, no direct link was found between the composition of microbial community in the BAC filter and that in its effluent.

Less than half of sequences recovered from Sample A could be classified to the genus level, but most of sequences recovered from Sample B and C could be affiliated with the putative bacterial genera. The putative genera were affiliated with Alphaproteobacteria, Betaproteobacteria, Gammaproteobacteria, Actinobacteria, Armatimonadetes, Bacteroidetes, Cyanobacteria, and Planctomycetes (Figs. 4, 5, 6, 7). The distribution of identified bacterial genera is much different from one previous study (Norton

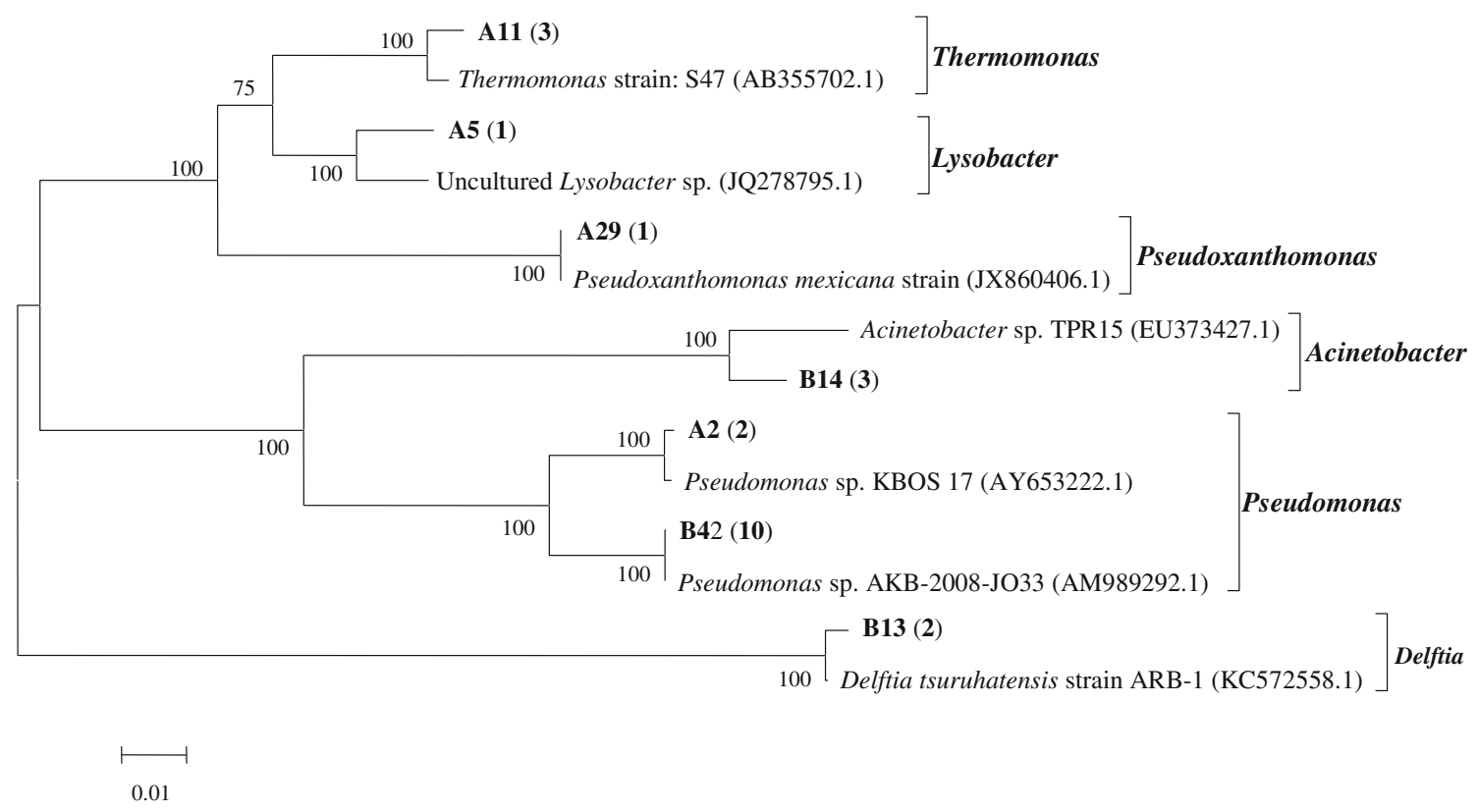

Fig. 6 Phylogenetic tree of representative 16S rRNA gene sequences assigned with putative genus within Gammaproteobacteria and reference sequences from GenBank. The obtained sequences beginning with 'A,' 'B,' and 'C' were referred to sequences recovered from Sample A, Sample B, and Sample C, respectively. Sample A, B, and $\mathrm{C}$ represent raw water, the sand filter effluent, and the BAC filter effluent, respectively. The bold number in parentheses represents the numbers of the sequences in the same genus. Numbers at the nodes indicate the levels of bootstrap support based on neighbor-joining analysis of 1,000 resampled datasets. Bootstrap values $<50$ are not shown. The bar represents $1 \%$ sequence divergence 


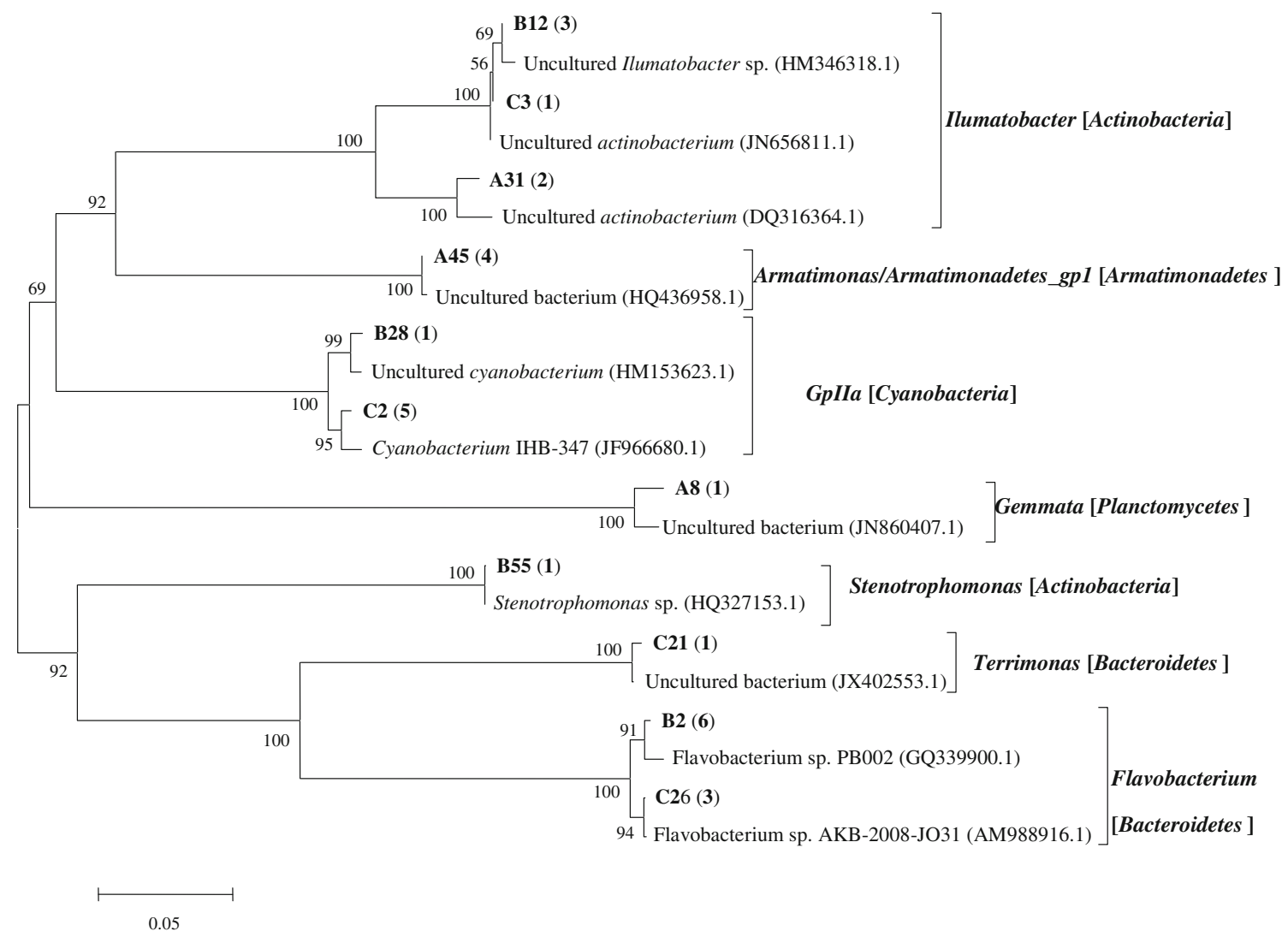

Fig. 7 Phylogenetic tree of representative 16S rRNA gene sequences assigned with putative genus within Actinobacteria, Armatimonadetes, Bacteroidetes, Cyanobacteria, and Planctomycetes, and reference sequences from GenBank. The obtained sequences beginning with 'A,' 'B,' and 'C' were referred to sequences recovered from Sample A, Sample B, and Sample C, respectively. Sample A, B, and C

and LeChevallier 2000). The genus compositions of the three samples were much different, and only Acidovorax, Polynucleobacter, and Ilumatobacter were shared among the three samples. Armatimonas/Armatimonadetes_gpl, Limnohabitans, and Thermomonas were the three largest genus groups in Sample A. Pseudomonas, Acidovorax, and Flavobacterium were dominant in sample B. However, Acidovorax was predominant in Sample C.

In this study, HPCs decreased dramatically through the treatment processes, and the HPCs in the sand filter effluent and the BAC filter effluent complied with the international quality standards (Pavlov et al. 2004). However, this might not necessarily ensure good microbiological quality of drinking water. In the sand filter effluent and the BAC filter effluent, microorganisms from several bacterial genera (Pseudomonas, Acinetobacter, Sphingomonas, and Novosphingobium) associated with opportunistic infections were found (Figs. 4, 6). Therefore, intense monitoring of the bacterial community changes through drinking water treatment processes will be necessary. represent raw water, the sand filter effluent, and the BAC filter effluent, respectively. The bold number in parentheses represents the numbers of the sequences in the same genus. Numbers at the nodes indicate the levels of bootstrap support based on neighbor-joining analysis of 1,000 resampled datasets. Bootstrap values $<50$ are not shown. The bar represents $5 \%$ sequence divergence

\section{Conclusion}

Treatment processes resulted in the change of HPCs. Molecular analysis indicated bacterial population diversity dramatically changed through the treatment processes, while Betaproteobacteria was dominant in raw water, the sand filter effluent, and the BAC filter effluent.

Acknowledgments This work was financially supported by the Major Science and Technology Program for Water Pollution Control and Treatment in China (No. 2009ZX07423-003).

\section{References}

APHA, Awwa, WEF (1995) Standard methods for the examination of water and wastewater, 19th edn. American Public Health Association, Washington, DC

Berry D, Xi CW, Raskin L (2006) Microbial ecology of drinking water distribution systems. Curr Opin Biotechnol 17(3):297-302

Burlingame GA, Suffet IH, Pipes WO (1986) Predominant bacterial genera in granular activated carbon water treatment systems. Can J Microbiol 32(3):226-230 
China Environmental Protection Agency (2002) Methods for water and wastewater determination. China Environmental Science Press, Beijing

Domingo JWS, Meckes MC, Simpson JM, Sloss B, Reasoner DJ (2003) Molecular characterization of bacteria inhabiting a water distribution system simulator. Water Sci Technol 47(5):149-154

Eichler S, Christen R, Holtje C, Westphal P, Botel J, Brettar I, Mehling A, Hofle MG (2006) Composition and dynamics of bacterial communities of a drinking water supply system as assessed by RNA- and DNA-based 16S rRNA gene fingerprinting. Appl Environ Microbiol 72(3):1858-1872

Feng S, Zhang XJ, Wang QF, Wan R, Chen C, Xie SG (2012) Heterogeneity of ammonia-oxidizing community structures in a pilot-scale drinking water biofilter. Int Biodeterior Biodegrad 70:148-152

Feng S, Chen C, Wang QF, Zhang XJ, Yang ZY, Xie SG (2013a) Characterization of microbial communities in a granular activated carbon-sand dual media filter for drinking water treatment. Int J Environ Sci Technol 10(5):917-922

Feng S, Chen C, Wang QF, Yang ZY, Zhang XJ, Xie SG (2013b) Microbial community in a full-scale drinking water biosand filter. J Environ Biol 34:321-324

Huang Y, Zou L, Zhang SY, Xie SG (2011) Comparison of bacterioplankton communities in three heavily polluted streams in China. Biomed Environ Sci 24(2):140-145

Kasuga I, Shimazaki D, Kunikane S (2007) Influence of backwashing on the microbial community in a biofilm developed on biological activated carbon used in a drinking water treatment plant. Water Sci Technol 55(8-9):173-180

Kormas KA, Neofitou C, Pachiadaki M, Koufostathi E (2010) Changes of the bacterial assemblages throughout an urban drinking water distribution system. Environ Monit Assess 165(1-4):27-38

Li X, Upadhyaya G, Yuen W, Brown J, Morgenroth E, Raskin L (2010) Changes in the structure and function of microbial communities in drinking water treatment bioreactors upon addition of phosphorus. Appl Environ Microbiol 76(22):7473-7481

Liao XB, Chen C, Chang CH, Wang Z, Zhang XJ, Xie SG (2012) Heterogeneity of microbial community structures inside the upflow biological activated carbon (BAC) filters for the treatment of drinking water. Biotechnol Bioprocess Eng 17(4):881-886

Liao XB, Chen C, Wang Z, Wan R, Chang CH, Zhang XJ, Xie SG (2013) Changes of biomass and bacterial communities in biological activated carbon filters for drinking water treatment. Process Biochem 48(2):312-316

Lu PP, Chen C, Wang QF, Wang Z, Zhang XJ, Xie SG (2013) Phylogenetic diversity of microbial communities in real drinking water distribution systems. Biotechnol Bioprocess Eng 18(1):119-124

Niemi RM, Heiskanen I, Heine R, Rapala J (2009) Previously uncultured $\beta$-Proteobacteria dominate in biologically active granular activated carbon (BAC) filters. Water Res 43(20):5075-5086

Norton CD, LeChevallier MW (2000) A pilot study of bacteriological population changes through potable water treatment and distribution. Appl Environ Microbiol 66(1):268-276
Pavlov D, de Wet CME, Grabow WOK, Ehlers MM (2004) Potentially pathogenic features of heterotrophic plate count bacteria isolated from treated and untreated drinking water. Int $\mathrm{J}$ Food Microbiol 92(3):275-287

Pinto AJ, Xi CW, Raskin L (2012) Bacterial community structure in the drinking water microbiome is governed by filtration processes. Environ Sci Technol 46(16):8851-8859

Poitelon JB, Joyeux M, Welte B, Duguet JP, Prestel E, DuBow MS (2010) Variations of bacterial 16S rDNA phylotypes prior to and after chlorination for drinking water production from two surface water treatment plants. J Ind Microbiol Biotechnol 37(2):117-128

Revetta RP, Pemberton A, Lamendella R, Iker B, Domingo JWS (2010) Identification of bacterial populations in drinking water using 16S rRNA-based sequence analyses. Water Res 44(5):1353-1360

Sartory DP, Gu HY, Chen CM (2008) Comparison of a novel MPN method against the yeast extract agar (YEA) pour plate method for the enumeration of heterotrophic bacteria from drinking water. Water Res 42(13):3489-3497

Schloss PD, Handelsman J (2005) Introducing DOTUR, a computer program for defining operational taxonomic units and estimating species richness. Appl Environ Microbiol 71(3):1501-1506

Soonglerdsongpha S, Kasuga I, Kurisu F, Furumai H (2011) Comparison of assimilable organic carbon removal and bacterial community structures in biological activated carbon process for advanced drinking water treatment plants. Sustain Environ Res 21(1):59-64

Tamura K, Dudley J, Nei M, Kumar S (2007) MEGA4, molecular evolutionary genetics analysis, MEGA software version 4.0. Mol Biol Evol 24(8):1596-1599

Villarreal JV, Schwartz T, Obst U (2010) Culture-independent techniques applied to food industry water surveillance: a case study. Int J Food Microbiol 141(SI 1):S147-S155

Wang Q, Garrity GM, Tiedje JM, Cole JR (2007) Naïve Bayesian classifier for rapid assignment of rRNA sequences into the new bacterial taxonomy. Appl Environ Microbiol 73(16):5261-5267

Wang Y, Wan R, Zhang SY, Xie SG (2012) Anthracene biodegradation under nitrate-reducing condition and associated microbial community changes. Biotechnol Bioprocess Eng 17(2):371-376

Williams MM, Domingo JWS, Meckes MC, Kelty CA, Rochon HS (2004) Phylogenetic diversity of drinking water bacteria in a distribution system simulator. J Appl Microbiol 96(5):954-964

Yapsakli K, Cecen F (2010) Effect of type of granular activated carbon on DOC biodegradation in biological activated carbon filters. Process Biochem 45(3):355-362

Zhang SY, Wang QF, Xie SG (2012) Molecular characterization of phenanthrene-degrading methanogenic communities in leachatecontaminated aquifer sediment. Int $\mathrm{J}$ Environ Sci Technol 9(4):705-712

Zwart G, Crump BC, Agterveld MK, Hagen F, Han SK (2002) Typical freshwater bacteria: an analysis of available 16S rRNA gene sequences from plankton of lakes and rivers. Aquat Microb Ecol 28(2):141-155 